\author{
HEART FAILURE, DEPRESSION AND EXERCISE \\ Areti Tsaloglidou ${ }^{1}$, Konstantinos Koukourikos ${ }^{2}$, Alexios Savvidis ${ }^{3}$, Lambrini \\ Kourkouta ${ }^{4}$ \\ ${ }^{1}$ Department of Nursing, International Hellenic University, Greece \\ ${ }^{2}$ Department of Nursing, International Hellenic University, Greece \\ ${ }^{3}$ Department of Physical Education and Sports, Aristotle University of \\ Thessaloniki, Greece \\ ${ }^{4}$ Department of Nursing, International Hellenic University, Greece
}

\begin{abstract}
.
Introduction: Patients with heart failure have high rates of physical disability, based on self-reported difficulty in performing daily living activities. Depression is also a disease entity that has a high co-morbidity in combination with heart failure. Beyond the usual medical care of heart failure, there is a plethora of research on the contribution of exercise to cardiovascular parameters and to the muscular system of patients with heart failure, its effect on their quality of life and relief of depression symptoms.

Purpose: The purpose of this study is to highlight the positive effect of exercise on patients with heart failure experiencing depression.

Methodology: The study material consisted of articles on the topic, found in Greek and international databases such as: Google Scholar, Mednet, Pubmed, Medline and the Hellenic Academic Libraries Association (HEAL-Link), using the appropriate keywords: heart failure, depression, exercise programs.

Results: Depression affects the clinical course and prognosis of patients with heart failure. The coexistence of depression and chronic heart failure leads to an increase in mortality. The benefits of exercise, therefore, in patients with heart failure and depression have a positive impact on the patients' quality of life by contributing to increasing their functional status, reducing their re-admissions to the hospital and relieving the symptoms of depression.

Conclusions: The high incidence of depression in patients with chronic heart failure requires measures to prevent it, such as exercise. Health professionals need to help patients understand their condition and follow therapeutic guidelines, as well as therapeutic exercise, which can improve their lifestyle and behavior, and help them prevent depression symptoms and promote their quality of life.
\end{abstract}

\title{
INTRODUCTION
}

Heart failure is a common and serious condition with major morbidity and mortality worldwide. As life expectancy increases, so does the need to deal with cardiovascular disease more effectively and improve patients' quality of life. (European Society of Cardiology, 2012)

Depression is also a disease entity that has a high morbidity with heart failure. The close relationship between major depression and heart failure has been shown in many studies. (Johansson et al, 2006) Furthermore, beyond the usual medical care of heart failure, there is a plethora of research on the contribution of exercise to cardiovascular parameters and to the muscular system of patients with heart failure, its effect on their quality of life and relief of depression symptoms. (Jiang et al, 2004) 
The purpose of this study is to highlight the positive effect of exercise on patients with heart failure experiencing depression.

The study material consisted of articles on the topic, found in Greek and international databases such as Google Scholar, Mednet, Pubmed, Medline and the Hellenic Academic Libraries Association (HEAL-Link), using the following keywords: heart failure, depression, and exercise.

\section{Depression and heart failure}

Depression affects the clinical course and prognosis of patients with heart failure. Several studies have emphasized the relationship between depression and poor prognosis. (Jiang et al, 2007)

In the study of Sherwood et al (2013), 204 patients with heart failure were assessed for severity of heart failure and depression based on a BDI (Beck Depression Inventory) scale. After a mean follow-up of three years patients with clinically severe depressive symptoms (BDI score $\geq 10$ ) had a high risk of hospitalization or death. The severity of depressive symptoms has proven to play an important role in this, rather than the use of antidepressant drugs. (Sherwood, 2013)

There are still several studies indicating that the coexistence of depression and chronic heart failure leads to an increase in mortality. (Jing et al, 2004) Patients with heart failure who had moderate to severe depression had a five-fold increased risk of mortality compared to those without depression. Depression is often associated with a loss of motivation and interest in daily activities, exercise, sleep disorders and appetite changes, with a corresponding change in weight. This could explain the relationship between depression and mortality. (Faris et al, 2002;Rumsfeld et al, 2005)

It has also been found that depression affects perceptions about the severity of the disease and the patient's quality of life and not that severe heart failure causes depression. This contrasts with the traditional perception that depression occurs because of reduced functional ability due to heart failure. (Gottlieb, 2009)

Treatment of depression includes antidepressant medication, psychotherapy, a combination of them and other forms of treatment, (Christodoulou, 2004) while cardiac rehabilitation includes, among others, exercise programs.

\section{Exercise and heart failure}

Patients with heart failure have high rates of physical disability, based on self-reported difficulty in performing daily living activities. (Panagopoulou et al, 2013) As patients have reduced their ability to perform simple daily tasks, patients' quality of life has decreased, health care costs have increased as there is an increasing need for support services. The disease itself is an independent predictor of mortality. Knowing the factors that determine physical function in patients with heart failure is thus involved in improving the patient's quality of life and disease prognosis. (Adamopoulos et al, 2001)

Therefore, all patients with heart failure are encouraged to participate in exercise programs. Regular exercise of moderate intensity is recommended. Recent studies have documented both its efficacy, with an emphasis on improving quality of life, as well as its safety. (The CONSENSUS Trial Study Group, 1987) 
The exercises performed include aerobic exercise, strength training and combined exercises, which are personalized to the individual patient with heart failure. (Adams et al, 2008)

Physical activity to produce the desired results is based on some principles and programs in which patients with heart failure are not excluded. They just need to follow them to achieve the desired results: (Middleton S\& Middleton PG, 2002; Raven et al, 2015;Ponikowski et al, 2016)

- Authority adaptability (trainability): the person's ability to adapt to coaching (training) stimuli.

- Authority periodicity (periodization): refers to a systematic approach to modifying exercise program variables, which allows general adjustments and reduces the risk of overtraining.

- Special situations authority: refers to the ability to change an exercise program under the new circumstances, including any injuries, illnesses, medication, lack of recovery and overtraining symptoms.

- Principle of overtraining: refers to the adverse effects of the excessive activity and exercise.

- Principle of consistency (adherence): refers to the ability of trainees to be consistent with the exercise program.

- Restoration principle: refers to the optimization of post-exercise recovery.

During exercise, some physiological changes occur in the function of the cardiovascular system depending on the type of exercise the individual performs.

Regardless of the etiology, heart failure begins with damage to the pump function. However, symptoms and progression of the disease include changes in peripheral organs and activation of neurohormones. (Giannuzzi et al, 2003; Georgantas et al, 2014)

Both heart failure and damage to the peripheral organs are responsible for the patient's intolerance to exercise. Exercise facilitates correction, in part, for most peripheral abnormalities and tends to reduce neuro-hormonal stimulation in patients with heart failure without harmful effects on left ventricle recovery. (Tabet et al, 2009)

The benefits of exercise, therefore, in patients with heart failure and depression have a positive impact on the patients' quality of life by contributing to increasing their functional status, reducing their re-admissions to the hospital and relieving the symptoms of depression.

\section{CONCLUSIONS}

The high incidence of depression in patients with chronic heart failure requires measures to prevent it, such as exercise.

Health professionals need to help patients understand their condition and follow therapeutic guidelines, as well as therapeutic exercise, which can improve their lifestyle and behavior, and help them prevent depression symptoms and promote their quality of life.

\section{REFERENCES}

Adamopoulos S, Parissis J, Kroupis C, et al (2001) Physical training reduces peripheralmarkers of inflammation in patients with chronic heart failure. Eur Heart J 22:791-7 
Adams BJ, Carr JG, Ozonoff A, et al (2008) Effect of exercise training in supervised cardiacrehabilitation programs on prognostic variables from the exercise tolerance test. Am JCardiol, 101:1403-7

Christodoulou G.N. Depression. In: G.N. Christodoulou et al (2004) Psychiatry, Volume I, Beta Publications, Athens, 313-348

European Society of Cardiology (2012) ESC Guidelines for the diagnosis and treatment of acute and chronicheart failure. Eur Heart J, 33: 1787-1847

Faris R, Purcell H, Henein MY, Coats AJS.(2002) Clinical depression is common and significantly associatedwith reduced survival in patients with nonischaemic heart failure. Eur J Heart Fail, 4 :541-51

Georgantas A, Dimopoulos S, Tasoulis A, Karatzanos E, Pantsios C, Agapitou V,Ntalianis A, Roditis P, Terrovitis J, Nanas S.(2014) Beneficial effects of combined exercise training on early recovery cardiopulmonary exercise testing indices in patients withchronic heart failure. Journal of Cardiopulmonary Rehabilitation and Prevention, 34 (6) :378-385

Giannuzzi P, Temporelli PL, Corra U, et al (2003) Antiremodeling effect of longterm exercisetraining in patients with stable chronic heart failure: results of the Exercise in Left Ventricular Dysfunction and Chronic Heart Failure (ELVD-CHF) Trial. Circulation, 108:554-9

Gottlieb SS, Kop WJ, Ellis SJ, Binkley P, Howlett J, O'Connor C, et al (2009) Relation of depression toseverity of illness in heart failure (from Heart Failure and a Controlled Trial Investigating Outcomes ofExercise Training [HF-ACTION]). Am J Cardiol, 1;103(9):1285-9

Jiang W, Kuchibhatla M, Clary GL, Cuffe MS, Christopher EJ, Alexander JD, et al. (2007) Relationshipbetween depressive symptoms and long-term mortality in patients with heart failure. Am Heart J, 154(1):102-8

Jiang W, Kuchibhatla M, Cuffe MS, Christopher EJ, Alexander JD, Clary GL, et al. (2004) Prognostic value ofanxiety and depression in patients with chronic heart failure. Circulation, 30;110(22):3452-6

Jing W, Kuchibhatla M, Cuffc MS, et al. (2004) Prognostic value of anxiety and depression in patients withchronic heart failure. Circulation, 110: 3452-6

Johansson P, Dahlström U, Broström A. (2006) The measurement and prevalence of depression in patientswith chronic heart failure. Prog Cardiovasc Nurs, 21(1):28-36

Middleton S, Middleton PG. "Assessment, investigations, skills, techniques andmanagement". In J. Pryor \& A. Prasad (Eds.)(2002) "Physiotherapy for respiratory andcardiac problems". London: Churchill Livingstone 
Panagopoulou et al (2013) NTproBNP: an important biomarker in cardiac diseases. Curr Top Med Chem, 13 (2) :82-94

Ponikowski, P. et al. (2016). ESC Guidelines for the diagnosis and treatment of acuteand chronic heart failure. The Task Force for the diagnosis and treatment of acute andchronic heart failure of the European Society of Cardiology (ESC)

Raven, Wasserman, Squires, Murray (2015) Physiology of Exercise. Textbook, Lagos Dimitrios

Rumsfeld JS, Jones PG, Whooley MA, et al (2005) Depression predicts mortality and hospitalization in patients with myocardial infarction complicated by heart failure. Am Heart J, 150: 961-7

Sherwood L. (2013). Human Physiology: FromCells to Systems. Cengage Learning

Tabet J. Y., Meurin P., Driss A. B., Weber H., Renaud N., Grosdemouge A., BeauvaisF., Solal A. C. (2009) Benefits of exercise training in chronic heart failure. Archives of Cardiovascular Disease, 102, 721 - 730

The CONSENSUS Trial Study Group (1987) Effects of enalapril on mortality in severe congestive heartfailure: results of the Cooperative North Scandinavian Enalapril Survival Study. N Engl J Med, 316:1429-1435 